\title{
Expected political participation and demographic changes in Europe
}

\author{
Mojca Rožman and Diego Cortés
}

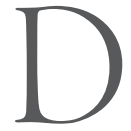

uring the last two decades, politics in western societies have faced several challenges. For example, Parvin and Saunders (2018) outline increasing political inequality, the decline of political participation and voter incompetence as some of these major challenges. The European Union (EU) has been no exemption to this and it is currently undergoing one of its most serious political crisis since its establishment. A key ingredient for this crisis has been an increasingly polarized society across several civic and political domains. For example, in May 2019 it was the first time in 40 years that the center-left / centerright European parliamentary coalition lost its majority; going from the previously secured $54 \%$ of the seats to just $43 \%$. In many occasions, both right-wing populist parties and liberal green parties outperformed the traditional political parties. Migration has been a central, but not exclusive, issue fueling this political and societal polarization. In this light, the purpose of this paper is to explore whether changes in expected political participation of young European adults during the last decade can be linked with the political crisis associated with the arrival of migrants seeking asylum in Europe.

Political participation refers to the engagement of the public in different activities affecting politics. Van Deth (2019) presents the core features of political participation after which any "voluntary, nonprofessional activity concerning government, politics, or the state" represents an example of political participation. Defined as such, participatory activities are for example, voting, demonstrating, signing a petition, etc. Voting is vital in a system of representative democracy. Elections make a fundamen- 
tal contribution to democratic governance, which is conducted through representatives. They enable voters to select leaders and hold them to account for their performance in office. Voting is a form of participation in which each citizen contributes the same assuming that they vote (one person, one vote). The electoral participation is usually measured by a turnout. A turnout represents the ratio between the number of people who attended the elections and the registered number of voters.

A fundamental challenge facing the political world is how to manage international forced migration, which appears to endure in the political agenda across countries as the forcibly displaced population continues to increase. ${ }^{I}$ This challenge has been aggravated in western societies by the rise of ethnic nationalist and populist leaders. In recent years, the Heads of State in the European Union and the United States have openly argued that migrants fleeing from violent conflicts pose a threat to national security. For example, leaders from Czech Republic, Hungary, Poland, and Slovakia strongly opposed hosting migrants from Syria, Afghanistan, and Iraq during 2015-2016, arguing that Muslims pose a threat to national security and identity. Similarly, in October 2018 the United States' President considered closing the southern border of the United States and deploying the Army on the basis of a "national emergency", when a migrant caravan of about 5,000 Central Americans, mostly women and children, fleeing from violent conflicts was heading towards the United States (for more examples see also Gantt Shafer, 2017).

Although the age of $\mathrm{I} 8$ years is the legal age for voting in many countries, from an academic and policy perspective it is relevant to focus on political and civic attitudes, perceptions and the behaviour of under aged citizens. Young adults are a good proxy for a nation's future social capital, as adolescence is a crucial period for civic socialization and engagement (Jennings and Stoker, 2004; Smith, 1999). Moreover, the academic literature on social capital suggests that political values and preferences can be transmitted across generations (Alford, Funk and Hibbing, 2005; Jennings and Niemi, 1968; Jennings, Stoker and Bowers, 2009). Furthermore, there is evidence that social networks, such as schools and the community, are important in determining young adults' social capital. Therefore, young adults' expected political participation is a relevant subject to study, as it might reflect future voter turnover, as well as actual societal political participation. 
The main objective of the paper is to investigate whether the recent immigration-related demographic change in Europe can be associated with changes in expected political participation of young adults. For this, we relied on three independent data sources from I2 EU-member countries. To capture young adults' expected political participation we relied on data from the International Civic and Citizenship Study (ICCS), a cyclical large-scale assessment in education implemented by the International Association for the Evaluation of Educational Achievement (IEA). In this paper, we used data collected for ICCS 2009 and 2016 in each of the I2 selected countries. Moreover, we used data compiled by Eurostat, which captures the number of asylum applications that were lodged in each of the selected countries. Finally, we used data on national voter turnout as reported by the International Institute for Democracy and Electoral Assistance (International IDEA, https://www.idea.int/ data-tools/country-view/264/40).

We began our analysis by looking at the relationship between the change in young adults' expected political participation and the rate of asylum application within a country. We observe changes between years 2009 and 2016 that should capture the changes related to the increased migration into Europe starting in 2015 . We found a positive correlation between the change in the expected electoral participation and the national asylum application rates. A higher rate of asylum applications is associated with an increase of expected electoral participation in selected European countries.

To complement this finding, we proceeded by investigating whether expected political participation of young adults is associated with actual voter turnouts in the country. We observed this relationship at two time points, first around the year 2009 and second around the year 2016. We found a positive relationship between the percentage of $8^{\text {th }}$ graders that certainly expect to vote in a country and the actual voter turnouts in both time points. This suggests that a higher voter turnout is associated with a larger proportion of students expecting to participate in national elections. This relationship is stronger in 2016 than in 2009. The result is in line with previous research findings in the literature, which point at social networks (i.e., family, school, and community) as determinant factors on civic and political engagement.

The remaining sections of this paper are structured as follows. In the next section, we review the academic literature pertinent to this research study. In Section 3, we describe the data employed in our empirical analysis. We continue by providing our results in Section 4. Finally, we present our conclusions in Section 6. 


\section{Literature Review}

In this section, we review the academic literature related to this research paper. In particular, we focus on two main strands of research bodies. The first one relates to the scientific relevance of studying the (expected) civic and political engagement of eighth graders (i.e., the target population of ICCS). The literature suggests two reasons for this. First, young adulthood is a key formation phase for civic and political socialization and engagement, indicating that eighth graders are a good proxy for a nation's future social capital. For example, Jennings and Stoker (2004) report that pre-adulthood civic engagement, measured as involvement in voluntary organizations, builds predispositions and skills; which they argue are relevant for civic and political engagement later in life. In addition, Smith (1999) documents how political and civic involvement in adulthood is associated with religious participation, participation in extracurricular activities and extensive connection to others during earlier stages of life.

The second reason relates to the extensive evidence on the literature suggesting that young adults' civic and political attitudes, perceptions, and behaviour are a reflection of societal attitudes, perceptions, and behaviour; highlighting the relevance of studying adolescents' political and civic engagement. In particular, this literature underscores the relevance of social networks as a critical channel of social capital transmission. For example, Alford, Funk and Hibbing (2005), Jennings and Niemi (1968), and Jennings, Stoker and Bowers (2009) present evidence on the within-family correlation of political values and civic attitudes and behaviour. This suggests that, to some extent, civic and political engagement in pre-adulthood is associated to parental civic and political engagement. Moreover, the school and neighborhood environment have been proven strong determinants of individuals' civic and political attitudes, perceptions and behaviour. For example, Bischoff (2016) suggests that student diversity and the existence of a micro-political environment are two potential mechanisms for civic learning at schools. Similarly, Campbell (2006) emphasizes the importance of communities and schools on shaping individual's civic life. In particular, he proposes a positive relationship between the level of homogeneity within the community and an individual's political and civic engagement.

The second strand of research our paper relates to is the academic work investigating how the recent arrival of migrants into Europe impacted political outcomes and civic engagement of native populations. In particular, this literature has focused on changes in local attitudes about and the political behaviour driven by immigration. For example, Dinas et al. 
(2019) report that across the Greek islands on the Aegean Sea, exposure to migrant seeking asylum in Europe induced sizable and lasting increases in locals' hostility towards refugees, immigrants, and Muslim minorities. They also find that exposure increases support for restrictive immigration and asylum policies, as well as political engagement to effect those exclusionary policies. Similarly, Hangartner et al. (2019) show that the vote share for the Greek Golden Dawn political party increased in communities exposed to this migration wave. Finally, Steinmayr (2016) documents that the vote shares secured by right-wing political parties in the 2015 national election in Austria decreased in communities which hosted asylum seekers in that same year.

\section{Data}

We relied on data from three different sources to investigate the association between the recent arrival of migrants into Europe and the expected political participation of young adults. Firstly, we used data from EU member countries participating in ICCS. ICCS is a cyclical international comparative large-scale assessment in education conducted by the IEA in 2009 and 2016. Overall, 38 countries participated in the study in 2009, while 24 did in 2016 . We restricted our analysis for countries participating in both cycles of the study (i.e., 2009 and 2016). That is, we used data from the following 12 countries: Bulgaria, Denmark, Estonia, Finland, Italy, Latvia, Lithuania, Malta, Netherlands, Norway, Slovenia and Sweden. We excluded data from Belgium, as only the Flanders region participated in both cycles of ICCS and data from the other two sources is not disaggregated in this regard. In all the countries included in our analysis, the legal age of voting is 18 and voting is not compulsory.

The survey design of ICCS parallels the design of well-known largescale assessments in education (i.e., the Trends in Mathematics and Science Study, the Progress in International Reading Literacy Study, and the Programme in International Student Assessment). The target population of the study is students in Grade 8. For each participating country, a representative sample of schools and students is selected using a (stratified) two-stage sampling design. At the first stage, schools are selected independently across sampling strata with a probability proportional to their size. Intact classrooms are then selected within sampled (and participating) schools using a simple random sample (second stage). This implies that selection probabilities of students vary across schools and strata, which underlines the importance of using sampling weights in the analysis to obtain unbiased population estimates (we discuss this further later in the paper). In Table I, we show school and student sample sizes for the 
2009 and 2016 cycles for the selected EU member countries. Importantly, data from all selected countries met all quality standards established by the IEA to ensure a representative sample of the target population.

Table i. Sample sizes for selected countries participated in ICCS 2009 and 2016.

\begin{tabular}{lcccc} 
& \multicolumn{2}{c}{2009} & \multicolumn{2}{c}{2016} \\
\cline { 2 - 5 } Country & Schools & Students & Schools & Students \\
\cline { 2 - 5 } Denmark & 158 & 3257 & 147 & 2931 \\
\hline Estonia & 193 & 4508 & 184 & 6254 \\
\hline Finland & 140 & 2743 & 164 & 2857 \\
\hline Italy & 176 & 3307 & 179 & 3173 \\
\hline Latvia & 172 & 3366 & 170 & 3450 \\
\hline Lithuania & 150 & 2761 & 147 & 3224 \\
\hline Malta & 199 & 3902 & 182 & 3631 \\
\hline Norway & 55 & 2143 & 47 & 6271 \\
\hline Slovenia & 129 & 3013 & 148 & 2844 \\
\hline Sweden & 163 & 3070 & 145 & 3264 \\
\hline
\end{tabular}

The primary objective of ICCS is to measure students' civic knowledge, their understanding of concepts and issues related to civic and citizenship, as well as their civic attitudes and engagement (Schulz et al., 2008; Schulz et al., 2016). Besides being assessed on their civic and citizenship competences, participating students also respond to a questionnaire, which aims to capture students' contextual characteristics, as well as their civic attitudes, perceptions and behaviours. The underlying methodology of the study's design aims at guaranteeing the comparability of results across countries. Furthermore, a special emphasis is put on making results comparable over time within countries. This is important, given the cross-country nature of our analysis and the country-level panel structure of our working database.

To capture students' expected political participation, we relied on data from one question that was administered in both ICCS cycles. This question reads as follows: "Listed below there are different ways adults can take an active part in society. When you are an adult, what do you think you will do?". In specific, in our analysis we focused on the item "Vote in <national elections>", to which students could respond using one of the following statements: "I would certainly do this", "I would probably do

2 In ICCS 2009 the first part of the question was "Listed below there are different ways adults can take an active part in political life". 
this", "I would probably not do this", or "I would certainly not do this". This was item B in question 32 for ICCS 2009 ( IS $_{2} \mathrm{P}_{32} \mathrm{~B}$ ) and item $\mathrm{B}$ in question 31 for ICCS 2016 (IS $\left.3 \mathrm{G}_{3} \mathrm{I} B\right)$. In column 2 of Table 2, we show for each selected country - the estimated proportion of $8^{\text {th }}$ grade students that in ICCS 2009 expressed they certainly would vote in a national election. We did the same using data from ICCS 2016 in column 5. In most countries, the likelihood of a student expressing he or she would vote in a national election is higher in ICCS 2016 than in ICCS 2009 . Moreover, a cross-country comparison of our variable of interest reveals a similar pattern within each cycle, that is, data from Estonia shows the lowest percentage of students that certainly would vote in both ICCS cycles, while Nordic countries show the highest.

As a second source of information, we compiled data from Eurostat about asylum applicants from 2014 until 2018 [migr_asyappctzm] and total population on I January 2018 [demo_gind] from the selected EU member countries (https://ec.europa.eu/eurostat/data/database). Eurostat is the statistical office of the European Union situated in Luxembourg and its mission is to provide high quality statistics for Europe that enable comparisons between countries and regions. We used this information to construct the variable asylum application per 1o, ooo in habitants, as presented in column 8 . We defined this variable as the sum of all asylum applications between January 2014 and December 2018 within each country, divided by its total population, and multiplied it by $10,0 \circ 0$. Overall, across the selected countries, the asylum application rate fluctuates to a large extent, with Sweden reporting about 315,000 applications and Estonia reporting less than 7,000 in the observed period.

Finally, as a third source of data we relied on captures voter turnout in the selected countries. This information is available online from the International IDEA and consists of a comprehensive collection of voter turnout statistics in presidential and parliamentary elections since 1945 . We focused only on elections for national assembly (in some countries referred to as parliament, chamber of representatives or chamber of deputies) and took the voter turnout of the election proximate to each ICCS cycle. In column 4 from Table 2 we present the national voter turnout most proximate to ICCS 2009 for each country, while in column 3 we report the year in which the national election was held. Similarly, in column 7 we present the national voter turnout most proximate to ICCS 2016 for each country, while in column 6 we report the year in which the nation-

3 In ICCS 2009 the response options included the word "will" instead of "would". As the meaning of these words from the respondents point of view does not differ much, we can treat the response options as comparable. 
Table 2. Compiled data from ICCS, voter turnout database and Eurostat.

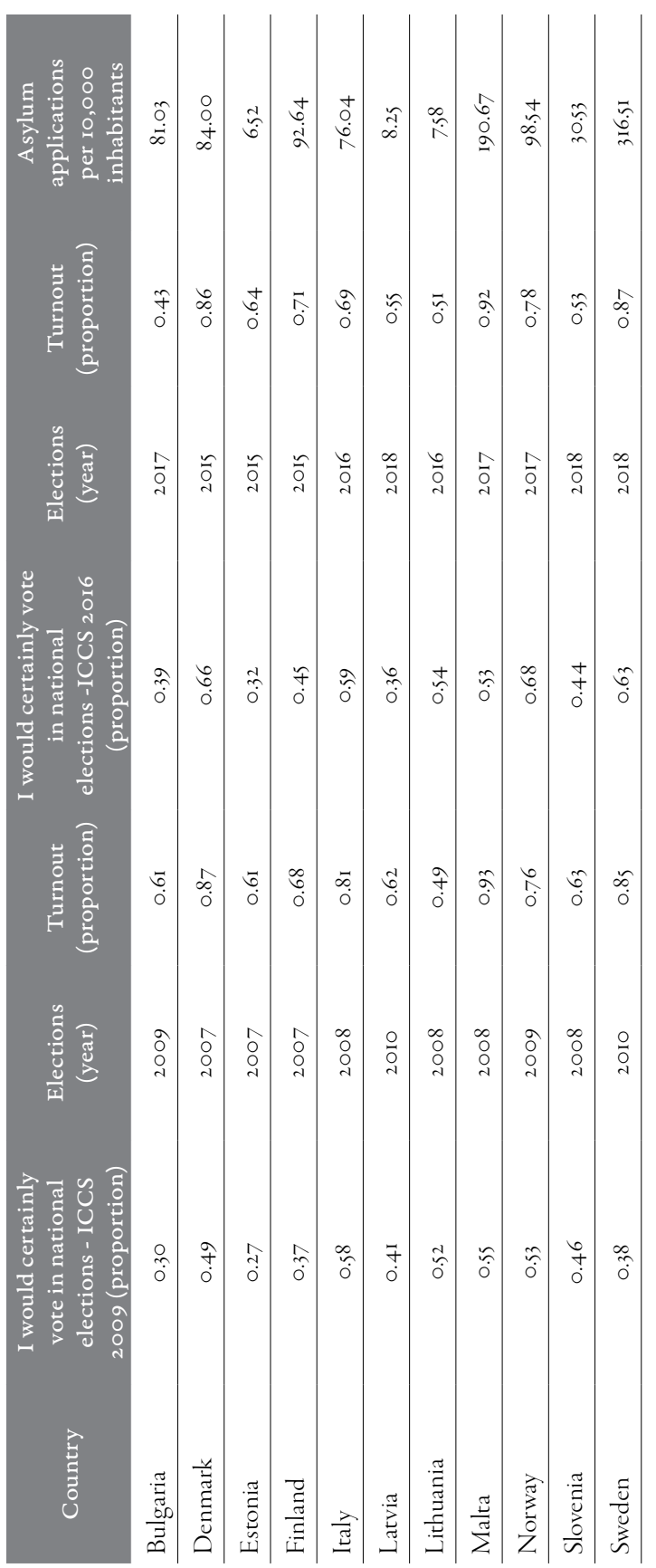


al election was held. All analyses in this paper were done using $\mathrm{R}$ version 3.5.I (R Core Team, 2018)

\section{Results}

\section{Changes in expected political participation and the European political crisis}

The primary objective of this research paper is to explore the association between the recent arrival of migrants into Europe and the expected political participation of young adults. In recent decades, immigration has become a highly politicized topic in Europe; largely, this socio political polarization has been intensified by the increasing challenge of managing forcibly displaced populations across EU country members. The case of Brexit has been a major social and political transformation within the continent ever since. In this light, with this paper we want to increase our understanding on the correlates between young adults' expected political participation and the political crisis associated with the arrival of migrants fleeing violence and political persecution into Europe in recent years.

To attain our objective, we look at the relationship between national asylum application rates and the change in young adults' political participation expectations, which we define as the difference between the estimated national proportion of eighth graders that certainly expect to vote, as documented by ICCS 2009 and ICCS 2016. In Figure I, we show a visual representation of the strong and positive relationship between these two variables (correlation coefficient is 0.60 ). On the $\mathrm{x}$-axis, we plot the national asylum application rate, while on the y-axis we plot the change in young adult's political participation expectations. This association suggests that countries with higher asylum application rates from 2014 to 2018 have, on average, a larger percentage of young adults willing to vote in national elections, relative to 2009 . Interestingly, young adults in Italy, Latvia, Malta, and Slovenia show a decrease in their expected political participation, while Scandinavian selected countries show the largest positive change in this variable.

In Figure $\mathrm{I}$ we also add the least-squares prediction line of regressing the national asylum application rate on the change in young adult's political participation expectations, with a $95 \%$ confidence interval of the predicted values (gray-shaded area). The line predicts that an increase of $\mathrm{I} O$ in the national asylum application rate will be associated with an increase in the change in young adults' political participation expectation of about 0.6 percentage points $(\mathrm{p}$-value $=0.05)$. 


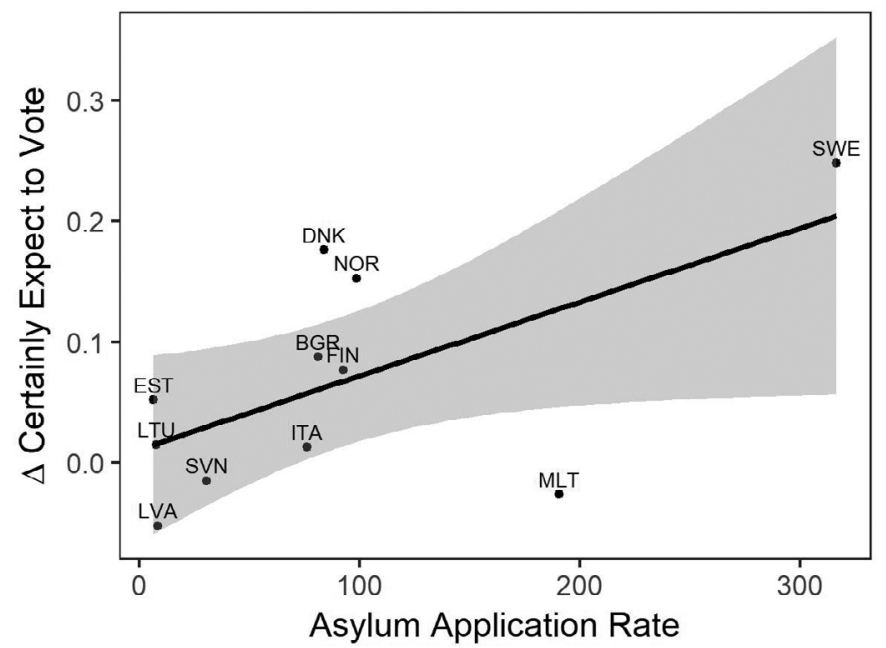

Figure r. Changes in expected voting participation and asylum application rates.

This result is relevant for two reasons. First, the arrival of migrants into Europe fueled a political debate on whether member countries have the legal and moral obligation to host asylum seekers. This became a major issue in the agenda of most political parties across EU-member countries in recent national elections. Therefore, the results we document above indicate that the increased political engagement of the European youth can be associated to the arrival of migrants and/or the political debate subsequently triggered. Second, as noted in the literature review, there is evidence in the literature that civic and political engagement of young adults is, to some extent, a reflection of societal civic and political engagement. This suggests that the arrival of migrants might not only be associated with the expected political behaviour of the young population, but rather to actual societal political engagement. We explore this last idea in the next section, in which we look at the correlation between eighth graders expected political participation and actual national voter turnout.

\section{Expected political participation and actual turnout}

We proceeded by providing empirical evidence on the correlates between contemporaneous young adults' political participation expectations and national voter turnouts, which underscores the relevance of the results presented in the previous section. For this, we relied on data from ICCS 2009 and 2016 and national turnout results for the countries selected in 


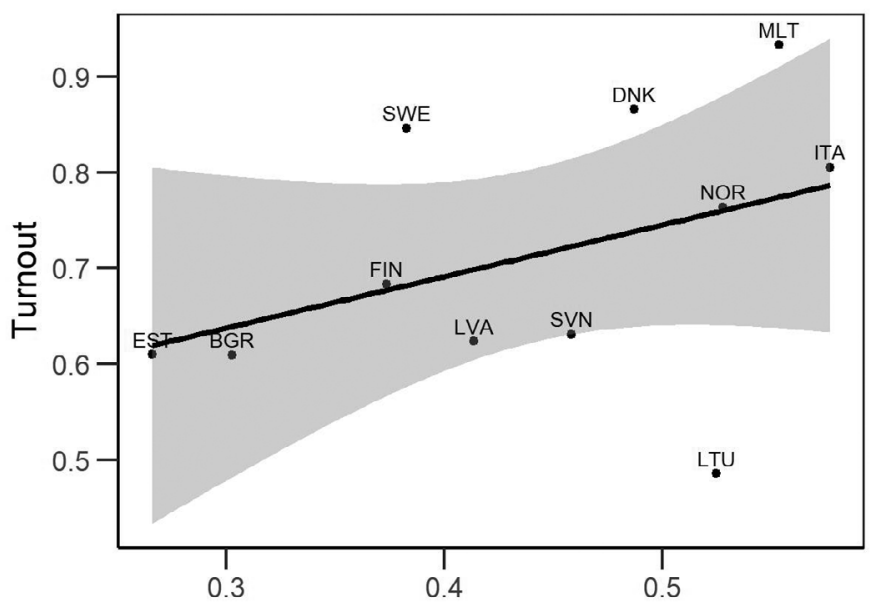

Certainly Expect to Vote (ICCS 2009)

Figure 2. Expected voting participation from ICCS 2009 and actual turnout.

our analysis. As outlined in the literature review section, there is extensive evidence about how social networks (i.e. household, community, and school environment) influence the formation of political and civic engagement. In this section, we provide empirical evidence that support this hypothesis.

We began by looking at the relationship between the estimated percentage of eighth grade students that certainly expect to vote in a country - as reported in ICCS 2009 - and the national voter turnout of the parliamentary election most proximate to 2009. For three countries specifically, we looked at the national voter turnout of the 2007 national election, for four countries the national election took place in 2008 , two in 2009 , and for two in 2010 (see column 3 in Table 2). In Figure 2, we show a visual representation of the positive and relatively strong relationship between these two variables (correlation coefficient is 0.40 ). On the $\mathrm{x}$-axis, we plot our measure of young adult's political participation expected in 2009 , while on the y-axis we plot the national voter turnout.

This relationship is evidence that supports the premise that young adults' expected political participation is a good approximation of actual participation in a society. Interestingly, students in Nordic countries are the most certain they would vote in a national election (Sweden, Denmark and Norway), while students in ex-communist countries (Lithuania, Estonia and Bulgaria) show the least expected political participation. 


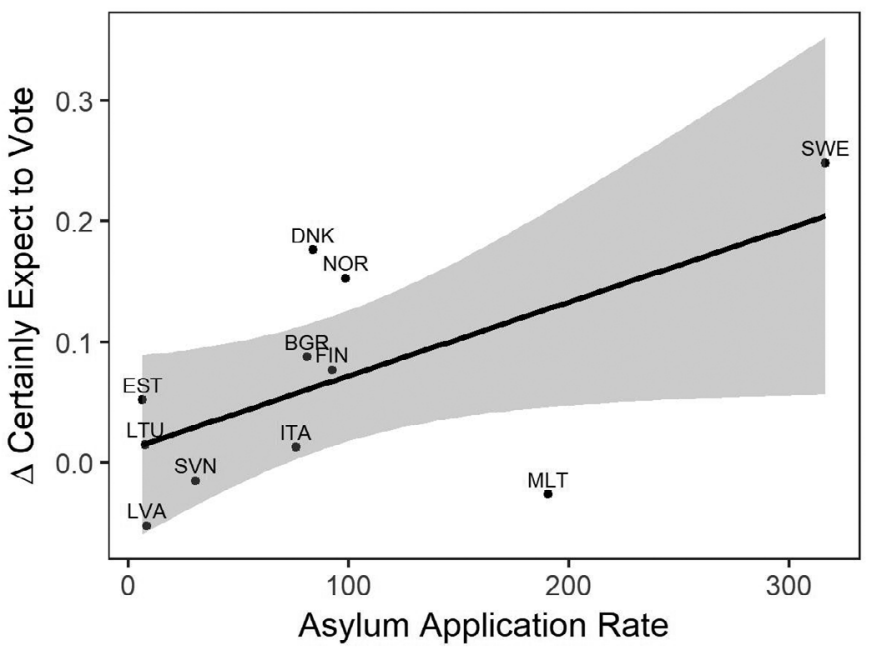

Figure 3. Expected voting participation from ICCS 2016 and actual turnout.

The black line represents the prediction line of regressing national voter turnouts on expected political participation and the grey shaded area represents the $95 \%$ confidence interval of the predicted values. An increase of one percentage point in the proportion of students that certainly expected to vote will be associated with an increase of about 0.5 percentage points in the actual turnout. This relationship is not statistically significant $(p=0.22)$.

We proceeded by conducting the same analysis using data from ICCS 2016. That is, we looked at the relationship between expected political participation and the election turnout most proximate to 2016 , i.e., when data for the ICCS study was collected. In specific, for three countries we looked at the national voter turnout of the 2015 national election, for two countries the national election took place in 2016 , for three in 2017 , and three in 2018 (see column 6 in Table 2). In Figure 3, we show a visual representation of the positive and strong relationship between these two variables (correlation coefficient is 0.65 ). On the $\mathrm{x}$-axis, we plot our measure of young adult's political participation expectation in 2016, while on the y-axis we plot the national voter turnout.

This relationship is yet another piece of evidence that supports the hypothesis that young adults' expected political participation is a good approximation of actual participation in a society. The black line represents the prediction line of regressing national voter turnouts on expected polit- 


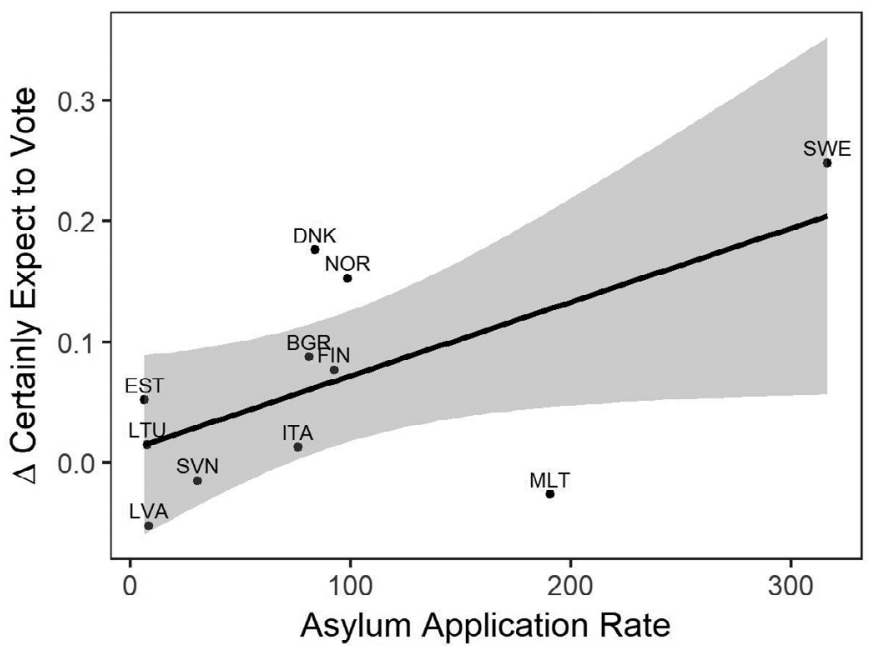

Figure 4. Changes in turnouts and the asylum application rates.

ical participation and the grey shaded area represents the $95 \%$ confidence interval of the predicted values. An increase of one percentage point in the proportion of students that certainly expected to vote will be associated with an increase of about 0.9 percentage points in the actual turnout. Contrary to 2009 , the relationship is statistically significant $(p=0.03)$.

Overall, Figure 2 and Figure 3 suggest two important conclusions. First, in line with previous research findings, we obtain systematic evidence on the positive relationship between young adults' expected political participation and actual participation in a society. The second conclusion is that, among the countries under study, the relationship became stronger in 2016. These two findings highlight the relevance of the positive association we found between the recent arrival of migrants into Europe and the expected political participation of young adults.

As a last result, in Figure 4 we show a visual representation of the relationship between national asylum application rates and the change in national voter turnout (i.e., column 7 minus column 4 in Table 2). On the $\mathrm{x}$-axis, we plot the national asylum application rate, while on the $\mathrm{y}$-axis we plot change in national voter turnout. This association suggests that countries with higher asylum application rates from 2014 to 2018 have, on average, a larger and positive change in the previous two national elections. The correlation coefficient between these two variables is 0.24 . This result is of a smaller magnitude but in line with the positive and strong association found between young adults' expected political participation and 
asylum application rates (Figure I) and the positive correlation between young adults' expected political participation and actual turnout (Figure 2 and Figure 3). A possible explanation for the relatively smaller correlation is that the year in which national elections were held across the selected countries varies. That is, the most proximate election to 2016 for three countries was in 2015 , possibly before the arrival of migrants into Europe; while, for the other three countries the most proximate election to 2016 was in 2018 (two years after the arrival of migrants).

The black line presents the least-squares prediction line and the grey shaded area shows a 95\% confidence interval of the predicted values. The biggest drop in voter turnout can be observed in Bulgaria, Italy and Slovenia where the difference in turnout between the two selected elections was more than io percentage points. A positive trend in attending elections can be observed in Estonia, Lithuania, Finland, Norway and Sweden, while the participation in elections did not change much during time in Denmark and Malta. As expected, the estimated effect of asylum application rates on the change in voter turnouts is not statistically significant $(p=0.47)$.

\section{Conclusions}

Young adults play a crucial role in society as they represent the future social capital of a nation. This makes studying civic and political attitudes, perceptions, and behaviour very relevant from an academic and policy perspective. In this paper we have combined data from three data sources to study the relationship between changes in expected voting participation and recent immigration waves in Europe. We relied on data collected for ICCS study conducted in 2009 and 2016 , a voter turnout database, and country-level official statistics. We have found that the change in expected electoral participation of students is associated to the number of asylum applications within a country. To gather some evidence that the self-reported data from students reflect the society and societal changes we examined the relationship between expected voting participation and actual voter turnouts in the country. We have found a positive association between these two variables. Our results point to the conclusion that there is an association between the recent migration movements in Europe and the increased political participation in countries. This association is reflected in students and their expectations for future civic and political engagement.

The limitations of our study follow. First, the data we used from ICCS was collected across countries at the same point in time, while data from national election turnouts follow a country specific time track (i.e., column 3 
and column 6 in Table 2). Therefore, it might be that the lack of a standardized unit of time when looking at changes over time adds important noise to our empirical analysis. Hence, the results of the difference in turnouts are suggestive and should be interpreted with caution. Second, the data we used in this study is cross-sectional, therefore a causal interpretation of the results is not possible. Finally, we used aggregated data by country; hence, we neglected any within country variation that might be important.

Finally, our research provided yet further evidence on the association between community homogeneity and political engagement. As suggested by Campbell (2006), increasing the level of heterogeneity in a community will likely increase the level of political engagement within a society. A demographic change, such as the recent arrival of migrants into Europe, is likely to increase the heterogeneity of a community in many dimensions, which in turn might spark the political engagement of its citizens (either in favour for or against the demographic change). In this paper, we observe this association at the country-level. A promising line of research would be to explore this hypothesis using within-country variation. Exploiting community-level variation on arrival of migrants and using the rich battery of data provided by ICCS could provide important insights on this exciting research topic.

\section{Literature}

Alford, J. R., Funk, C.L., and Hibbing, J. R. (2005) Are political orientations genetically transmitted? American Political Science Review 99, pp. I53-167.

Bischoff, K. (2016) The civic effects of schools: Theory and empirics. Theory and Research in Education I 4(I), pp. 91-I06. https://doi. org/10.1177/1477878515619794

Campbell, D. (2006) Why We Vote: How Schools and Communities Shape Our Civic Life. Princeton University Press. Retrieved from http:// www.jstor.org/stable/j.ctt7sinx

Dinas, E., Malakos, K., Hangartner, D., and Xefteris, D. (2019) Waking up the Golden Dawn: Does exposure to the refugee crisis increases supports for extreme-right parties? Political Analysis 27(2), pp. 244-254. https://doi.org/10.1017/pan.2018.48

Gantt Shafer, J. (2017) Donald Trump's “Political Incorrectness”: Neoliberalism as Frontstage Racism on Social Media. Social Media + Society, pp. I-IO. https://doi.org/I0.1177/2056305117733226 
Hangartner, D., Dinas, E., Marbach, M., Malakos, K., and Xefteris, D. (2019) Does exposure to the refugee crisis makes natives more hostile? American Political Science Review II3 (2), pp. 442-455.

Jennings, M. K., and Niemi, R. G. (1968) The transmission of political values from parent to child. American Political Science Review 62, pp. I69-184.

Jennings, M. K., and Stoker, L. (2004) Social trust and civic engagement across time and generations. Acta Politica 39(4), pp. 342-379.

Jennings, M. K., Stoker, L., and Bowers, J. (2009) Politics across generations: Family transmission reexamined. The Journal of Politics $7 \mathrm{I}(3)$, pp. $782-799$.

Parvin, P., and Saunders, B. (2018). The Ethics of Political Participation: Engagement and Democracy in the 2ist Century. Res Publica 24(I), pp. 3-8. https://doi.org/10.1007/s11158-017-9389-7

R Core Team (2018) R: A language and environment for statistical computing. R Foundation for Statistical Computing, Vienna, Austria. URL https://www.R-project.org/

Smith, E. S. (1999) The effects of investment in the social capital of youth on political and civic behavior in young adulthood: A longitudinal analysis. Political Psychology 20(3), pp. 553-580.

Schulz, W., Fraillon, J., Ainley, J., Losito, B., and Kerr D. (2008) International Civic and Citizenship Education Study: Assessment Framework. IEA Secretariat: Amsterdam.

Schulz, W., Ainley, J., Fraillon, J., Losito, B., and Agrusti, G. (2016) IEA International Civic and Citizenship Education Study 2016: Assessment Framework. IEA Secretariat: Amsterdam.

Steinmayr, A. (2016) Exposure to refugees and voting for the far-right: (Unexpected) results from Austria. IZA Discussion Paper.

UNHCR (2018) Global Trends: Forced Displacement in 2017. Geneva: UNHCR.

Van Deth, J. W. (2016) What is Political Participation? Oxford Research Encyclopedia of Politics. Oxford: Oxford University Press. DOI: I0.1093/ acrefore/9780190228637.013.68

DOI: https://www.doi.org/10.32320/158I-6044.30(5-6)63-78 